\title{
Importancia del laboratorio en el diagnóstico de las micosis invasoras
}

\author{
ANA MARÍA GUZMÁN D.
}

\section{Importance of laboratory diagnosis in invasive mycosis}

The Mycology Laboratory is an increasingly important tool in the diagnosis of fungal diseases. Better methods, including blood cultures, solid media-cultures, antigen detection and molecular-based tests have emerged as a response to the increase of immunocompromised patients at risk of invasive fungal infections. Recently, criteria of proved, probable or possible fungal infections have been introduced, this criteria will be useful in the evaluation and standardization of the laboratory tests and will help to establish their clinical relevance.

Key words: Fungal infections, Invasive mycosis, Diagnosis.

\section{Generalidades}

Las micosis invasoras son cada vez más frecuentes en la práctica clínica, afectando especialmente a sujetos con grados variables de inmunocompromiso por causas como infección por el VIH y enfermedades hematológicas malignas. Además se presentan en forma secundaria a tratamientos agresivos como cirugía mayor, terapia anti retroviral, quimioterapia, trasplante de precursores hematopoyéticos y tratamientos antimicrobianos de amplio espectro. Estos tratamientos tienen como consecuencia que un número importante de pacientes sobrevive a su enfermedad de base pero, a su vez, son más susceptibles a infecciones por agentes oportunistas. Es así como un número creciente de hongos, que antiguamente se consideraban no patógenos, se han identificado como agentes causales de infecciones en este tipo de hospedero ${ }^{1-3}$.

Las infecciones invasoras por hongos son cuadros difíciles de reconocer, ya que tanto los síntomas como los signos clínicos son, a menudo, inespecíficos. Recientemente la EORTC y el NIAID (National Institute of Allergy and Infectious Diseases) han considerado tres pilares para el diagnóstico de las infecciones fúngicas invasoras en pacientes con cáncer y trasplante de precursores hematopoyéticos:
- factores predisponentes en el hospedero

- elementos clínicos-radiológicos

- hallazgos de laboratorio.

Estos factores considerados conjuntamente permitirían clasificar estas infecciones como demostradas, probables o posibles. Para clasificar una infección como demostrada, es suficiente el hallazgo de hongos en sangre o en un sitio normalmente estéril con un cultivo o examen directo, independientemente de la presencia de factores predisponentes en el hospedero o elementos clínico-radiológicos. Una infección probable es aquella en que existen factores predisponentes en el hospedero, elementos clínicos sugerentes y un estudio micológico positivo, pero no definitorio, como podría ser una serología de galactomanano positiva o un cultivo positivo de sitio no estéril. Una infección posible es aquella en que alguno de los tres elementos, ya sean los factores predisponentes, los elementos clínico-radiológicos o la micología, no está presente ${ }^{4,5}$.

Es importante destacar entonces, que la recuperación de hongos en un cultivo de una muestra proveniente de sitio no estéril, no es suficiente para confirmar una infección verdadera por hongos. Se deberá siempre diferenciar de una colonización en base a elementos clínicos y también considerar la posibilidad de que haya ocurrido

Unidad Docente Asociada Laboratorios Clínicos. Facultad de Medicina, Pontificia Universidad Católica de Chile.

Recibido: 12 diciembre 2003

Aceptado: 20 diciembre 2003 
una contaminación de la muestra durante la obtención o procesamiento de ella en el laboratorio.

El laboratorio de micología debe apoyar al médico clínico en el proceso diagnóstico de las infecciones fúngicas invasoras, disponiendo de técnicas adecuadas, rápidas y confiables, colaborando en el inicio de terapias antifúngicas apropiadas y precoces. El diagnóstico micológico tradicional se basa principalmente en la microscopia y el cultivo; sin embargo, actualmente el desarrollo está centrado en la búsqueda de metodologías rápidas como la detección de antígenos y/o anticuerpos y las técnicas de biología molecular $^{6}$. A continuación se revisan los principales aspectos de las diferentes metodologías disponibles en el laboratorio de micología.

\section{Muestras clínicas}

El mejor resultado microbiológico se obtiene cuando la muestra que se recibe en el laboratorio es recolectada en las mejores condiciones. Se debe considerar dependiendo de la localización (heridas, expectoración, secreción vaginal, lavado broncoalveolar, raspados de piel o fanéreos, líquidos de cavidades estériles, etc.) el volumen de muestra, la hora de su obtención, la necesidad de emplear medio de transporte, el tiempo de transporte y el tipo de muestra a estudiar ${ }^{7}$. En general, todas las muestras se obtienen en las mismas condiciones que para el estudio microbiológico habitual (Tabla 1). La muestra debe examinarse cuidadosamente, asegurando que sean

Tabla 1. Condiciones de recolección y transporte para muestras frecuentes recibidas en el laboratorio de micología

\begin{tabular}{|c|c|c|c|}
\hline Tipo de muestra & Recolección & Transporte & Observaciones \\
\hline Sangre & $\begin{array}{l}\text { Limpie la piel con alcohol } \\
70 \% \text {. Luego desinfecte con } \\
\text { povidona yodada, aplicando } \\
\text { concéntricamente hacia afuera. } \\
\text { Deje secar y realice la punción } \\
\text { venosa. Tome el máximo de } \\
\text { sangre recomendada para la } \\
\text { botella que se está utilizando. }\end{array}$ & $\leq 2 \mathrm{hr}$ a temperatura ambiente. & $\begin{array}{l}\text { Idealmente obtenga } 2 \text { botellas } \\
\text { separadas al menos por } 30 \\
\text { minutos de sitios de punción } \\
\text { diferentes. }\end{array}$ \\
\hline Líquido cefalorraquídeo & $\begin{array}{l}\text { Procedimiento médico. } \\
\text { Obtenga 1-2 ml. en tubo estéril }\end{array}$ & $\begin{array}{l}\text { Envíe de inmediato al } \\
\text { laboratorio (Ideal } \leq 15 \mathrm{~min} \text { ) } \\
\text { a temperatura ambiente. }\end{array}$ & \\
\hline $\begin{array}{l}\text { Líquidos de cavidades } \\
\text { estériles (ascítico, } \\
\text { pleural, pericárdico, } \\
\text { articular) }\end{array}$ & $\begin{array}{l}\text { Procedimiento médico, ya sea } \\
\text { por aspiración percutánea o } \\
\text { cirugía. Envíe la mayor } \\
\text { cantidad de muestra posible. }\end{array}$ & $\begin{array}{l}\text { Envíe de inmediato al } \\
\text { laboratorio (Ideal } \leq 15 \mathrm{~min} \text { ) } \\
\text { a temperatura ambiente. }\end{array}$ & \\
\hline Muestras respiratorias & $\begin{array}{l}\text { En caso de expectoración, } \\
\text { debe preferirse la primera de } \\
\text { la mañana, 2-3 ml. en frasco } \\
\text { estéril. Lavado broncoalveaolar: } \\
\text { de resorte médico }\end{array}$ & $\leq 2 \mathrm{hr}$ a temperatura ambiente. & $\begin{array}{l}\text { Se prefiere lavado bronco } \\
\text { alveolar o biopsia si existe } \\
\text { sospecha de infección } \\
\text { pulmonar invasora. }\end{array}$ \\
\hline Orina & $\begin{array}{l}\text { Recolecte entre } 50-200 \mathrm{ml} \text { de } \\
\text { orina matinal en frasco estéril }\end{array}$ & $\leq 2 \mathrm{hr}$ a temperatura ambiente. & $\begin{array}{l}\text { No se recomienda recolección } \\
\text { de } 24 \mathrm{hrs} \text {. }\end{array}$ \\
\hline Tejidos & Procedimiento médico & $\leq 2 \mathrm{hr}$ a temperatura ambiente. & \\
\hline Heridas, abscesos & $\begin{array}{l}\text { Se prefiere aspirado o biopsia. } \\
\text { Cuando sea posible, tome } \\
\text { trozo de pared del absceso. } \\
\text { Si no es posible, use torulado } \\
\text { de la zona. }\end{array}$ & $\leq 2 \mathrm{hr}$ a temperatura ambiente. & \\
\hline
\end{tabular}


procesadas las áreas más sospechosas de contener elementos infecciosos (necróticas, caseosas, hemorrágicas, etc).

\section{Técnicas diagnósticas}

\section{Microscopia}

La observación microscópica puede dar información preliminar sobre la presencia o ausencia de hongos en la muestra y también orientar sobre la especie causante de la infección debido a la observación de elementos micóticos característi$\cos ^{8}$. Algunos elementos que podremos observar al microscopio son levaduras, yemaciones, hifas septadas o aseptadas, pseudohifas, etc. (ver glosario).

Examen directo: el examen al fresco entre lámina y laminilla es un método de bajo costo, rápido y que no requiere equipamiento especial; sin embargo, debe ser realizado por personal entrenado. Su sensibilidad depende del tipo y cantidad de muestra y del número de microorganismos presentes en ella. Cuando la muestra tiene detritus celulares se utiliza hidróxido de potasio al $10 \%$, el cual clarifica de material orgánico y deja intactas las estructuras fúngicas. (Figura 1)

Tinción de Gram: también es una técnica barata y rápida, que nos permitirá observar levaduras yemantes o formando pseudohifas con mayor claridad que el examen directo (Figura 2); sin embargo, debe tenerse presente que los hongos filamentosos no se tiñen o lo hacen muy débilmente con tinción de Gram, por lo que si se sospecha la presencia de un hongo filamentoso, no debe utilizarse.

Tinción con blanco de calcoflúor: es una tinción fluorescente, rápida y útil en todo tipo de muestras incluyendo tejidos, y que requiere para la observación, menor entrenamiento que el examen directo al fresco. Esto se debe a que contrasta los elementos micóticos con gran claridad por la unión del blanco de calcoflúor con la quitina de la pared fúngica; sin embargo, tiene falsos positivos con fibras vegetales, colágeno o elastina $^{9,10}$. Si se dispone de microscopio de fluorescencia, es de elección para la búsqueda de hongos filamentosos que, como ya se comentó, no se tiñen con tinción de Gram (Figura 3).

Tinción de cápsula: esta técnica es útil para la búsqueda de Cryptococcus neoformans en mues- tras clínicas, especialmente LCR. Utiliza tinta china la cual destaca el material capsular como un halo claro (no teñido) alrededor de la levadura. En casos de criptococosis meníngea, logra una sensibilidad de alrededor de $75 \%{ }^{11}$ (Figura 4).

\section{Cultivos}

La siembra microbiológica es necesaria para lograr la identificación de especie de los diversos hongos comprometidos en infecciones fúngicas y permite además realizar estudio de susceptibilidad en caso de ser necesario. En general, si no hay suficiente material para realizar el examen directo y el cultivo, este último tiene prioridad por su mayor sensibilidad.

Hemocultivos: durante el último tiempo se ha desarrollado una gran variedad de sistemas automatizados de hemocultivos, los cuales en su botella estándar utilizan medios enriquecidos para cultivar un sinnúmero de microorganismos incluyendo los hongos; logra incluso superar métodos considerados de elección, como por ejemplo el hemocultivo por lisis centrifugación (Isolator®, Wampole Laboratories). El desarrollo reciente de botellas especiales para el cultivo de hongos en los sistemas automatizados conteniendo antibacterianos y agentes lisantes, no ha mejorado la recuperación respecto a las botellas estándares $^{12}$. El hallazgo de un hongo en sangre certifica el diagnóstico de una micosis invasora; sin embargo, el hemocultivo presenta una baja sensibilidad y se sabe que su positividad no supera el $50 \%$ en pacientes con candidiasis invasora comprobada por autopsia ${ }^{13}$. En el caso de los hongos filamentosos, aun cuando ellos estén invadiendo tejido, escasamente se encontrarán en sangre.

Cultivos en medio sólido: se pueden utilizar medios no inhibitorios como agar Sabouraud o agar cerebro-corazón para muestras provenientes de sitios estériles y medios inhibitorios que por contener antimicrobianos, evitan un crecimiento bacteriano excesivo para muestras provenientes de sitios no estériles. En estas muestras en que el cultivo es mixto, está demostrado que la siembra en medios corrientes deja de recuperar hasta $50 \%$ de los cultivos positivos para hon$\operatorname{gos}^{14}$.

\section{Detección de antígeno}

Se han descrito numerosas técnicas para la detección de antígenos fúngicos, algunas de ellas incluso disponibles comercialmente. 

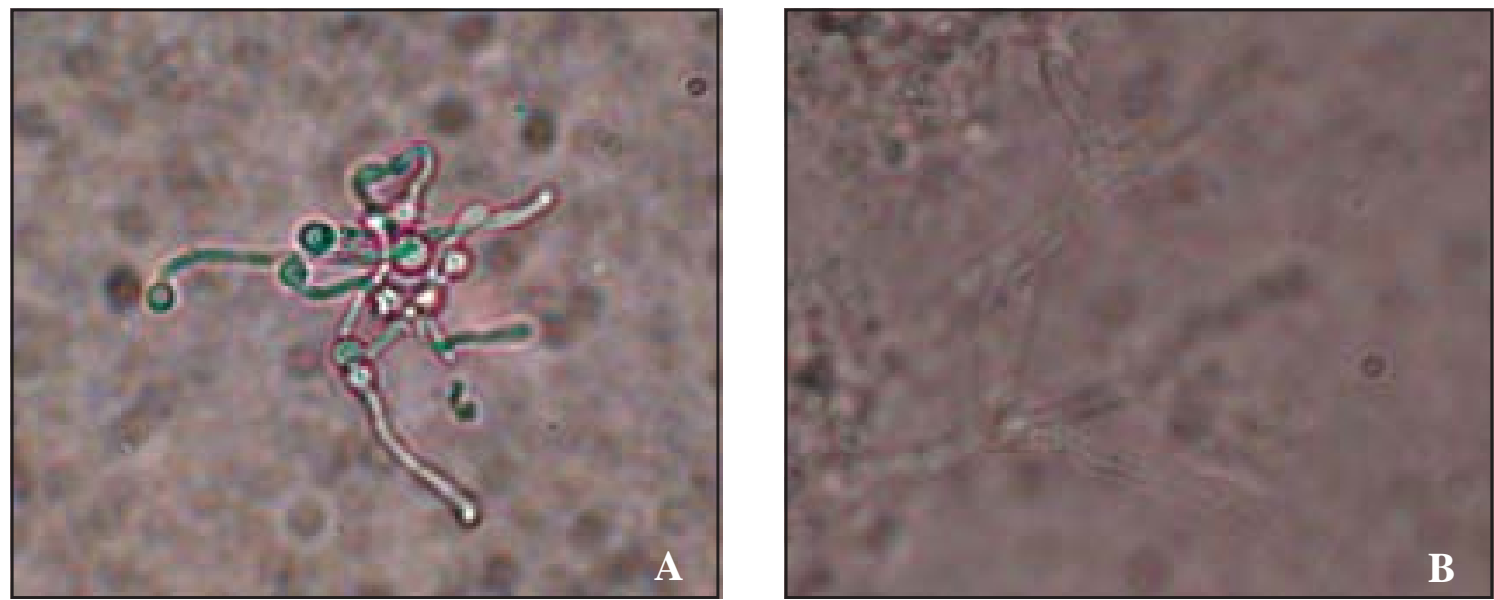

Figura 1. Examen directo al fresco (sin tinción), aumento 400x. A: levaduras filamentando, B: hifas aseptadas.

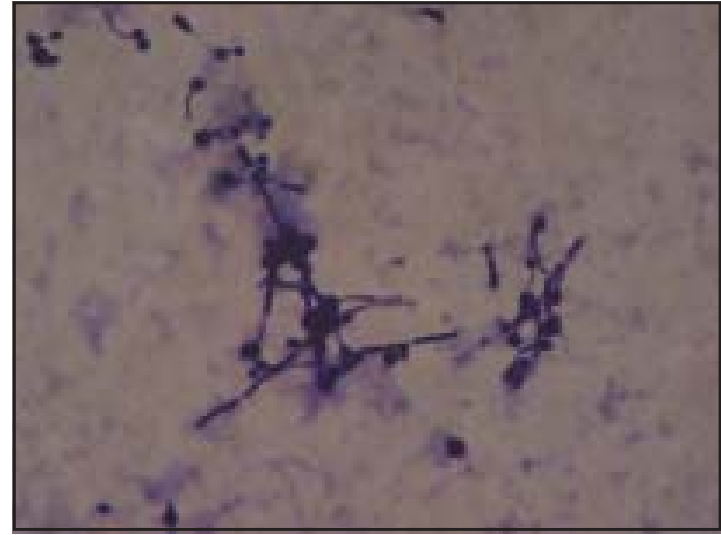

Figura 2. Tinción de Gram, aumento 400x. Se observan levaduras filamentando (pseudohifas), teñidas como estructuras Gram positivas.
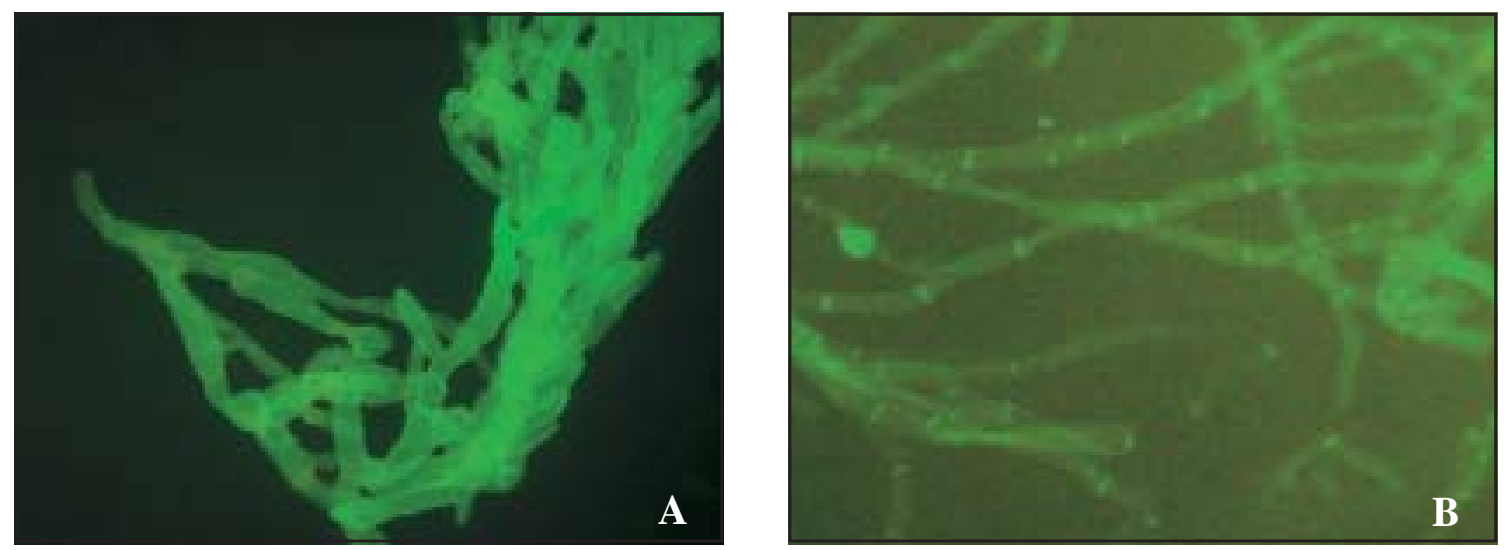

Figura 3. Tinción con blanco de calcoflúor, aumento 400x. A: hongo aseptado (Rhizopus sp). B: hongo septado (Aspergillus sp).

42
Figura 4. Tinción de cápsula (tinta china), aumento 400x. Se observa halo no teñido, correspondiente a cápsula, rodeando una levadura. 
Látex para Cryptococcus: este método de aglutinación se utiliza para la detección del polisacárido capsular de C. neoformans, tanto en suero como en LCR, con fines diagnósticos y de monitoreo de la terapia. Tiene una sensibilidad cercana al $95 \%$ y una especificidad entre 93 y $100 \%{ }^{15,16}$.

\section{Inmunofluorescencia para Pneumocystis} jiroveci (ex carinii): esta técnica utiliza anticuerpos monoclonales específicos contra determinantes antigénicos de la pared de los quistes y trofozoitos de $P$. jiroveci. Tiene una sensibilidad reportada cercana a $100 \%$ y una especificidad de alrededor de $96 \%{ }^{17,18}$.

Antigenemia para búsqueda de Aspergillus spp: recientemente se ha incorporado un inmunoensayo tipo "sandwich" comercial (Platelia Aspergillus®, BioRad) que utiliza un anticuerpo monoclonal dirigido contra la cadena lateral 1,5 $\beta$-D galactofuranósido del galactomanano. El ensayo tiene un límite de detección entre 0,5 y 1,0 $\mathrm{ng} / \mathrm{ml}$ de suero, superior a los $15 \mathrm{ng} / \mathrm{ml}$ de suero descrito para el látex existente previamente. En un estudio cuyo estándar de oro fue el cultivo y la histología, la sensibilidad fue de $92,6 \%$ y la especificidad de $95,4 \%$. El test fue positivo en promedio 6 días antes que la sospecha clínica ${ }^{19}$. Actualmente se considera que un examen positivo debe ser confirmado con una segunda muestra y forma parte de los criterios usados por EORTC y NIAID para definir micosis invasoras.

Detección de antígenos de Candida spp: entre ellos destaca Cand-Tec ${ }^{\circledR}$ (Ramco, Laboratories Inc., Houston, Tex.), método de aglutinación con partículas de látex para un antígeno termolábil no bien caracterizado, que en los diferentes estudios ha mostrado valores desde 25 hasta $100 \%$ de sensibilidad para el diagnóstico de candidiasis invasora, y por lo tanto no existe consenso sobre su utilidad clínica. Otras moléculas blanco como por ejemplo manano, enolasa y D-arabinitol, han sido estudiadas para el diagnóstico de candidiasis invasora, pero lamentablemente todos estos ensayos han tenido una utilidad muy limitada ${ }^{20,21}$.

\section{Biología molecular}

Debido a las dificultades tanto de sensibilidad, especificidad y retardo de las técnicas microbiológicas tradicionales, se han desarrollado durante la última década diversas técnicas en el campo de la biología molecular con gran potencial en el área del diagnóstico micológico, tanto para la pesquisa e identificación del agente causal como para la evaluación de clonalidad con distintos fines.

Entre las técnicas más difundidas está la amplificación por RPC, especialmente por su alta sensibilidad y rapidez. Esta técnica se ha implementado en diferentes aproximaciones: RPC con partidores especie o género -específicos, RPC y Southern blot, RPC y análisis con enzimas de restricción, RPC anidada, RPC en tiempo real, RPC con análisis de fragmentos y secuenciación ${ }^{22-24}$.

En relación a la pesquisa de hongos como agentes causales de infección en diferentes muestras clínicas, los blancos de amplificación más estudiados son el gen para la sub-unidad $18 \mathrm{~S}$ rRNA y las ITS (internal transcribed spacer) adyacentes, las que forman parte del operón del ARN ribosomal. Éste presenta regiones altamente conservadas, lo que permite la aplicación de RPC panfúngicos que detectan genéricamente hongos, y también regiones hipervariables en secuencia y/o tamaño, que permiten la identificación de la especie involucrada, ya sea por utilización posterior de sondas, electroforesis capilar para el análisis de fragmentos o secuenciación. Uno de los primeros trabajos que utilizó esta aproximación ${ }^{25}$ demostró su utilidad en pacientes con episodios de neutropenia y fiebre con sospecha de infección fúngica invasora. La sensibilidad analítica lograda fue de $1 \mathrm{ufc} / \mathrm{ml}$ de sangre, detectándose con dos muestras consecutivas de sangre hasta $100 \%$ de los pacientes con infección fúngica invasora. La RPC demostró ser el indicador más precoz de infección fúngica, precediendo la evidencia clínica y radiológica, y correlacionándose además con la respuesta a la terapia y evolución clínica. El uso de sondas específicas permitió identificar especie con una correlación de $100 \%$ con la identificación microbiológica. Estos hallazgos han sido confirmados por múltiples estudios ${ }^{26}$, por lo que en nuestro laboratorio se ha iniciado la implementación de estas técnicas (Figura 5). El mayor valor de la RPC es su alto valor predictor negativo, el cual permitiría descartar la presencia de una infección fúngica en forma precoz, disminuyendo el uso empírico de antifúngicos ${ }^{27,28}$. Sin embargo, estas técnicas se consideran aún en etapa de investigación y no son parte de los criterios de diagnóstico de micosis invasoras comentados previamente. Para su aplicación rutinaria se requiere mejorar aspectos técnicos como son la optimización de los métodos de extracción del ADN fúngico y disminuir las potenciales contaminaciones con hongos ambientales que puedan entregar falsos positivos. Otro aspecto a considerar es la excesiva sensibilidad de los métodos moleculares, que 

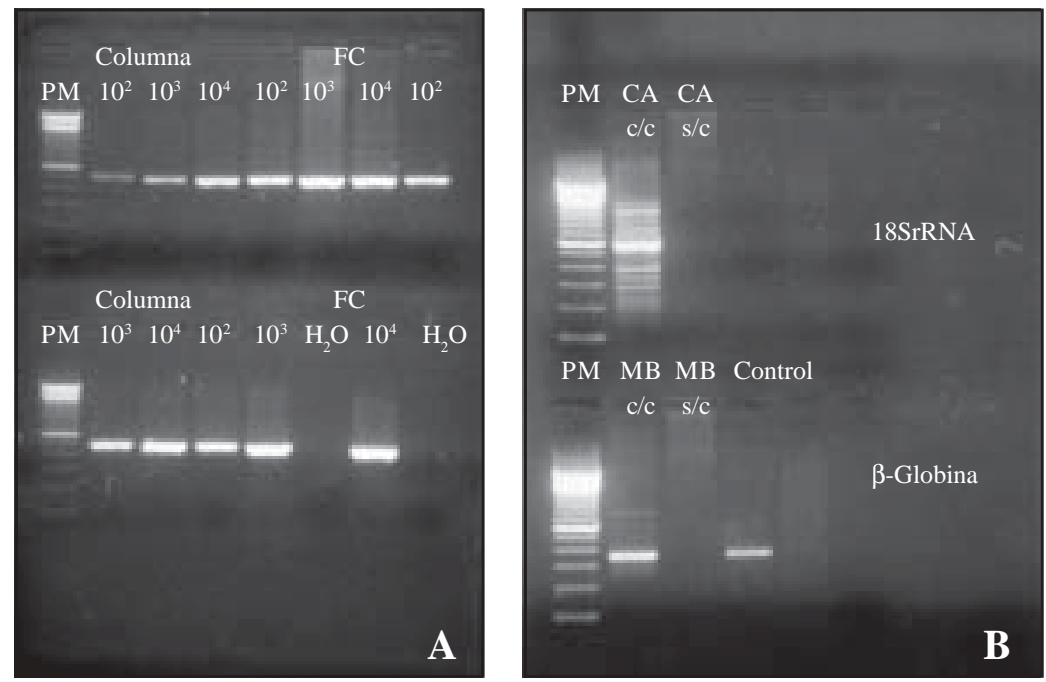

Figura 5. Reacción de polimerasa en cadena con partidor dirigido a región del $18 \mathrm{~S}$ rRNA. A: suspensiones entre $10^{2}$ y $10^{4}$ de Candida albicans preparadas en sangre (arriba) y en agua (abajo) con dos métodos de extracción diferentes (columna $v /$ $s$ fenolcloroformo (FC)). B: amplificación positiva de la misma región (18SrRNA) a partir de sangre de paciente con hemocultivos positivos para Candida albicans (CA) (arriba) con (CC) y $\sin$ (SC) columna de extracción. Amplificación del gen de la $\beta$-globina para verificar ausencia de inhibidores (abajo).

muchas veces hace difícil la interpretación de un resultado; el hallazgo de ADN fúngico no siempre es sinónimo de infección micótica. Los desafíos en esta área están en la correlación de los métodos propuestos con enfermedad invasora, y por sobre todo el desarrollo de técnicas estandarizadas y reproducibles.

Los métodos de biología molecular también han tenido aplicación en estudios de identifica- ción de especie en levaduras, especialmente aquellas en que la diferenciación por pruebas bioquímicas es difícil y/o insuficiente (Figura 6). Sin embargo, estas técnicas son todavía laboriosas y de costo elevado, por lo que no están disponibles en laboratorios asistenciales ${ }^{29,30}$.

En estudios epidemiológicos de evaluación de clonalidad, se han descrito diversas metodologías para detectar polimorfismos genéticos en levadu-
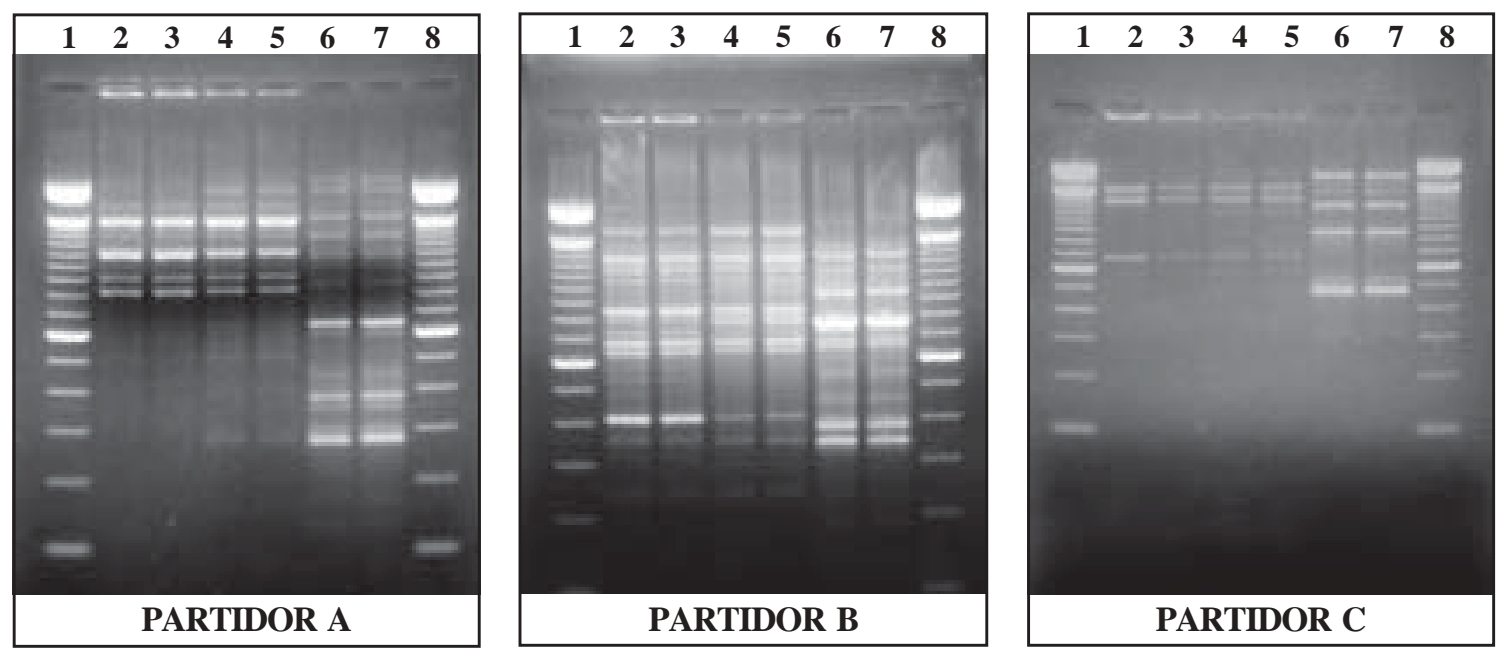

Figura 6. Diferenciación de Candida albicans y Candida dubliniensis por RAPD-PCR con tres partidores diferentes. Columnas : 1: MW 100bp, 2: C. albicans aislado 1, 3: C. albicans aislado 1, 4: C. albicans aislado 2, 5: C. albicans aislado 2, 6: C.dubliniensis aislado 1, 7: C.dubliniensis aislado 1, 8: MW 100bp. Patrón de bandeo obtenido con C. dubliniensis es diferente al de $C$. albicans con los tres partidores utilizados. 
$\operatorname{ras}^{31,32}$. El análisis con enzimas de restricción fue el primer método utilizado con este fin; sin embargo, el patrón de bandas resulta complejo y difícil de interpretar. La digestión con enzimas de restricción y posterior hibridación con sondas por Southern blot fue un avance importante presentando buena reproducibilidad, pero su laboriosidad y lentitud la hacen una técnica poco aplicable.

La electroforesis en campo pulsado es una técnica que también ha sido utilizada para la tipificación de Candida spp, ya que permite separar grandes fragmentos de ADN. El poder de discriminación de este método mejora si se utilizan enzimas de restricción que cortan con baja frecuencia en el genoma de las levaduras; sin embargo, también es una técnica laboriosa que requiere entre 5 y 7 días para obtener resultados. El análisis de ADN polimórfico amplificado por RPC (RAPD, Randomly Amplified Polymorphic DNA) y el PCR-fingerprinting también han sido utilizados para estudiar clonalidad en aislados $\operatorname{clínicos}^{33}$ (Figura 7) y más recientemente la tipificación por secuencias de múltiples loci o por análisis de microsatélites polimórficos ${ }^{34}$. Los métodos varían en su resolución y cada uno de ellos posee ventajas y desventajas específicas. No existiendo un método único de referencia, se recomienda por lo general utilizar más de un método para obtener resultados óptimos.
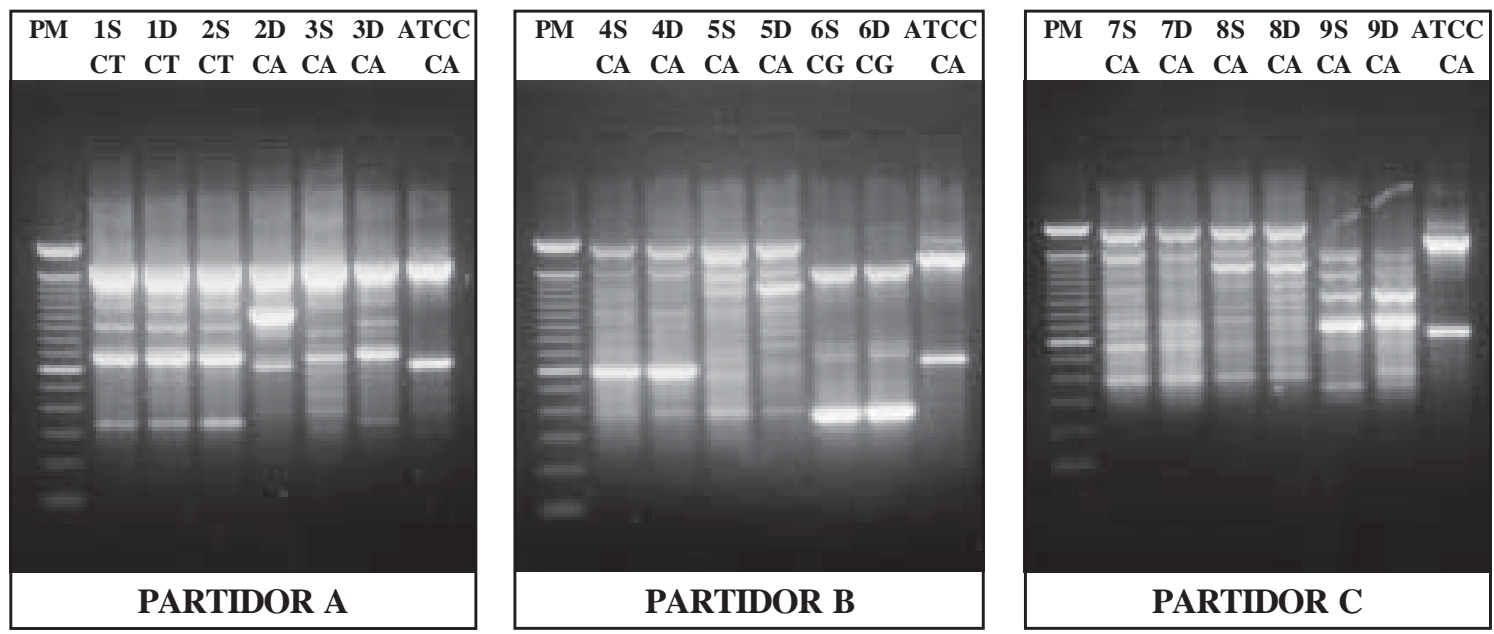

Figura 7. Estudio de clonalidad de las cepas aisladas en sangre (S) y deposición (D) en 9 pacientes con candidemia (CA: C. albicans, CT: C. tropicalis, CG: C. glabrata), por PCR-fingerprinting con partidor M13. El paciente $n^{\circ} 2$ tenía distinta especie en sangre (CT) que en deposición (CA). En los restantes 8 pacientes con la misma especie en sangre y deposición, se observa patrón de bandeo idéntico en todos los casos, excepto el paciente $n^{\circ} 3$.

\section{Resumen}

El laboratorio de micología constituye un pilar fundamental en el proceso diagnóstico de las infecciones fúngicas invasoras. El mejoramiento de los métodos de hemocultivos, cultivos en medio sólido, como también el desarrollo de nuevas técnicas para detección de antígenos y de los métodos de biología molecular, han emergido como una necesidad frente a un número creciente de pacientes con grados variables de inmunocompromiso, susceptibles de desarrollar este tipo de infecciones. Los criterios de infección fúngica demostrada, probable o posible recientemente establecidos, contribuirán a la evaluación y estandarización de estos y otros nuevos métodos de laboratorio, lo cual es fundamental para establecer su relevancia clínica.

\section{Agradecimientos}

A todos los integrantes de nuestro grupo de trabajo, sin los cuales no hubiese sido posible el desarrollo en esta área: Claudia Castillo, Pilar León, Eliana Romeo, Jaime Labarca y muy especialmente, a Helena Poggi por sus aportes, comentarios y revisión cuidadosa del manuscrito.

\section{Glosario}

Micología: estudio de los hongos y su biología.

Hongos: Reino constituido por organismos eucariontes heterótrofos absortivos que poseen quitina en su pared y carecen de clorofila. Pueden ser uni o multicelulares, macro o microscópicos. Por sus ca- 
racterísticas de crecimiento, en el laboratorio clínico se dividen en levaduras y hongos filamentosos.

Levaduras: son hongos unicelulares ovoideos, que pueden estar aislados o formando cadenas, con colonias similares a las de bacterias y que se dividen por yemación.

Filamentosos: son hongos multinucleados, con colonias algodonosas o vellosas. Forman estructuras filamentosas o hifas, las cuales pueden ser septadas o aseptadas y que crecen por elongación de los extremos.

Hifa: estructura filamentosa de los hongos, y que en conjunto forma el micelio. Pueden tener tabique o septo (hifa septada) o carecer de él (hifa aseptada o sifonada).

Pseudohifa: cadena de células, formada por levaduras yemantes y que semejan una hifa, pero que presentan constricciones a nivel del septo y que en el sitio de ramificación parten con un tabique.

Yemación: proceso de reproducción asexual característico de las levaduras, en el cual una nueva célula se genera a partir de una elongación de la célula madre.

\section{Bibliografía}

1.- Ostrosky-Zeichner L, Rex J, Bennett J, Kullberg B J. Deeply invasive candidiasis. Infect Dis Clin North Am 2002; 16: 821-35.

2.- Marr K, Patterson T, Denning D. Aspergillosis: pathogenesis, clinical manifestations and therapy. Infect Dis Clin North Am 2002; 16: 875-94.

3.- Walsh T J, Groll A H. Emerging fungal pathogens: evolving challenges to immunocompromised patients for the twenty-first century. Transpl Infect Dis 1999; 1:247-61.

4.- Donnelly J P. Symptoms and diagnosis of nosocomial fungal infections-State of the Art. Eur J Med Res 2002; 7: 192-9.

5.- Ascioglu S, Rex B, Bennett J E et al. Defining opportunistic invasive fungal infections in immunocompromised patients with cancer and hematopoietic stem cell transplants: an international consensus. Clin Infect Dis 2002; 34: 7-14.

6.- O'Shaughnessy E, Shea Y, Witebsky F. Laboratory diagnosis of invasive mycoses. Infect Dis Clin North Am 2002; 17: 135-58.

7.- Sutton D. Specimen collection, transport and processing: mycology. In: Murray PR, Baron EJ, Pfaller MA, et al editors. Manual of Clinical Microbiology. $8^{\text {th }}$ edition. Washington DC, American Society for Microbiology 2002: 1659-67.

8.- Merz W, Roberts G. Algorithms for detection and identification of fungi. In: Murray PR, Baron EJ, Pfaller MA, et al editors. Manual of Clinical Microbiology. $8^{\text {th }}$ edition. Washington DC, American Society for Microbiology 2002: 1668-85.

9.- Monheit J, Cowan D, Moore D. Rapid detection of fungi in tissues using calcofluor white and fluorescent microscopy. Arch Pathol Lab Med 1984; 108: 616-8.

10.- García P, Beltrán C, Guzmán A M, León P, Arredondo M, Fonseca X. Diagnóstico rápido de dos casos de mucormicosis con tinción de blanco de calcoflúor. Rev Chil Infect 2001; 18: 285-90.
11.- Chuck S, Sande M. Infections with Cryptococcus neoformans in the acquired immunodeficiency syndrome. N Engl J Med 1989; 321: 794-9.

12.- Mc Donald C, Weinstein M, Fune J, Mirrett S, Reimer L, Reller B. Controlled comparison of BacT/ALERT FAN aerobic medium and BACTEC fungal blood culture medium for detection of fungemia. J Clin Microbiol 2001; 39: 622-4.

13.- Gerain J, Sculier J P, Malengreaux A, Rykaert C, Themelin L. Causes of death in an oncologic intensive care unit: clinical and pathological study of 34 autopsies. Eur J Cancer 1990; 26: 377-81.

14.- Sandven P, Lassen J. Importance of selective media for recovery of yeast from clinical specimens. J Clin Microbiol 1999; 37: 3731-2.

15.- Saag M, Powderly W, Cloud G. Comparison of amphotericin B with fluconazole in the treatment of acute AIDS-associated cryptococcal meningitis. N Engl J Med 1992; 326: 83-9.

16.- Bennett J, Bailey J. Control for rheumatoid factor in the latex test for cryptococcosis. Am J Clin Pathol 1971; 56: 360-5.

17.- Kovacs J, Masur H. Diagnosis of Pneumocystis carinii pneumonia: improved detection in sputum with use of monoclonal antibodies. N Engl J Med 1988; 318: 58993.

18.- Cregan P, Yamamoto A, Lum A. Comparison of four methods for rapid detection of Pneumocystis carinii in respiratory specimens. J Clin Microbiol 1990; 28: 2432-6.

19.- Maertens J, Verhaegen J, Demuynck H et al. Autopsycontrolled prospective evaluation of serial screening for circulating galactomannan by a sandwich enzymelinked immunosorbent assay for haematological patients at risk for invasive aspergillosis. J Clin Microbiol 1999; 37: 3223-8.

20.- Stevens D. Diagnosis of fungal infections: current status. J Antimicrob Chemother 2002; 49 Suppl S1: 119.

21.- Pontón J, Moragues M, Quindós G. Non culture based methods. In: Calderone R. Editor. Candida and candidiasis. Washington DC, American Society for Microbiology 2002: 395-425.

22.- Loeffler J, Hebart H, Cox P, Flues N, Schumacher U, Einsele H. Nucleic acid sequence-based amplification of Aspergillus RNA in blood samples. J Clin Microbiol 2001: 39; 1626-9.

23.- Martin C, Roberts D, van der Weide M, Rossau R, Jannes G, Smith T, Maher M. Development of a PCRbased line probe assay for identification of fungal pathogens. J Clin Microbiol 2000: 38; 3735-42

24.- Ahmad S, Khan Z, Mustafa A, Khan Z. Seminested for diagnosis of candidemia: comparison with culture antigen detection and biochemical methods for species identification. J Clin Microbiol 2002: 40; 2483-9.

25.- Einsele H, Hebart H, Roller G, Löffler J, Rothenhöfer I et al. Detection and identification of fungal pathogens in blood by using molecular probes. J Clin Microbiol 1997: 35; 1353-60.

26.- Verweij P E, Meis JFGM. Microbiological diagnosis of invasive fungal infections in transplant recipients. Transpl Infect Dis 2000; 2: 80-7.

27.- Hebart H, Löffller J, Reitze $\mathrm{H}$ et al. Prospective screening by a panfungal polymerase chain reaction assay in patients at risk for fungal infections: Implications for the management of febrile neutropenia. Br J Haematol 2000: 111; 635-40.

28.- Williamson E C, Leeming J P, Palmer H M, Steward 
C G, Warnock D, Marks D I, Millar M R. Diagnosis of invasive aspergillosis in bone marrow transplant recipients by polymerase chain reaction. Br J Haematol 2000; 108 (1): 132-9.

29.- Sullivan D, Coleman D. Candida dubliniensis: characteristics and identification. J Clin Microbiol 1998; 36: 329-34.

30.- Sullivan D, Westerneng T, Haynes K, Bennett D, Coleman D. Candida dubliniensis sp. Nov: phenotypic and molecular characterization of a novel species associated with oral candidosis in HIV-infected individuals. Microbiology 1995; 141: 1507-21.

31.- Soll DR. The ins and outs of DNA fingerprinting the infectious fungi. Clin Microbiol Rev 2000: 13: 332-70.

32.- Pujol C, Joly S, Lockhart SR, Noel S, Tibayrenc M,
Soll D R. Parity among the randomly amplified polymorphic DNA method, multilocus enzyme electrophoresis, and Southern blot hybridization with the moderately repetitive DNA probe $\mathrm{Ca} 3$ for fingerprinting Candida albicans. J Clin Microbiol 1997; 35: 2348-58.

33.- Steffan P, Vazquez JA, Boikov D, Xu C, Sobel J D, Akins R A. Identification of Candida species by randomly amplified polymorphic DNA fingerprinting of colony lysates. J Clin Microbiol 1997; 35: 2031-9.

34.- Bretagne S, Costa J, Besmond C, Carsique R, Calderone R. Microsatellite polymorphism in the promoter sequence of the elongation factor 3 gene of Candida albicans as the basis for a typing system. J Clin Microbiol 1997; 35: 1777-80.

Correspondencia a:

Ana María Guzmán D

E-mail: amguzman@med.puc.cl 